\title{
Selective coral mortality associated with outbreaks of Acanthaster planci L. in Bootless Bay, Papua New Guinea
}

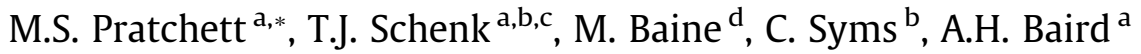 \\ ${ }^{a}$ ARC Centre of Excellence for Coral Reef Studies, James Cook University, Townsville, Qld 4811, Australia \\ ${ }^{\mathrm{b}}$ School of Marine and Tropical Biology, James Cook University, Townsville, Qld 4811, Australia \\ ${ }^{\mathrm{c}}$ WA Fisheries and Marine Research Laboratories, P.O. Box 20, North Beach, WA 6920, Australia

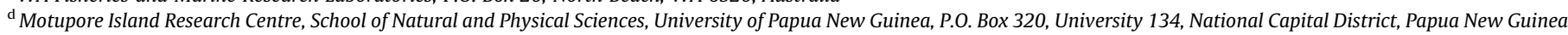

\section{A R T I C L E I N F O}

Article history:

Received 25 February 2008

Received in revised form 27 January 2009

Accepted 1 March 2009

\section{Keywords:}

Coral reefs

Crown-of-thorns

Disturbance

Effects-population

Predation

Scleractinian corals

\begin{abstract}
A B S T R A C T
Population outbreaks of crown-of-thorns sea star (Acanthaster planci L.) remain one of the most significant biological disturbances on tropical coral reefs although the increasing attention given to other threats has greatly limited recent progress in understanding the cause and consequences of this phenomenon. In September 2005 dramatic increases in the abundance of A. planci were observed on reefs within Bootless Bay, Central Province, Papua New Guinea, where few crown-of-thorns have previously been reported. Densities of $A$. planci peaked at 162 sea stars per hectare and caused extensive coral mortality. This outbreak killed upwards of $55 \%$ of live corals, reducing overall coral cover from $42.4 \%$ in 2005 down to just $19.1 \%$ in March 2006. Declines in coral cover were largely driven by widespread mortality of Acropora spp. which dominated reef assemblages prior to the outbreak. The extensive depletion of Acropora spp. greatly altered the coral composition as well as the physical structure of reef habitats. In the absence of any other major disturbances these coral communities are likely to quickly recover, but this outbreak highlights the ongoing contribution of $A$. planci to degradation of coral reef environments.
\end{abstract}

Crown Copyright $\odot 2009$ Published by Elsevier Ltd. All rights reserved.

\section{Introduction}

Environmental disturbances have a significant influence on the structure and dynamics of coral reef communities, which appear particularly susceptible to a wide range of disturbances (Hughes and Connell, 1999; Baird et al., 2005; Wilson et al., 2006; Bruno and Selig, 2007). Among the most studied and one of the most significant disturbances on tropical coral reefs, are outbreaks of the coral-eating crown-of-thorns sea star, Acanthaster planci Linnaeus 1758 (see reviews by Pearson, 1981; Moran, 1986; Birkeland and Lucas, 1990). In reviewing recovery of coral communities from disturbance, Pearson (1981) suggested that disturbances caused by $A$. planci were more extensive and widespread than that caused by any other natural or anthropogenic disturbances. However, emerging threats associated with climate change, such as coral disease (Bruno et al., 2007) and bleaching (Hughes et al., 2003) are rapidly becoming the major focus of coral scientists throughout the world (Knowlton, 2001).

Climate-induced coral bleaching is now the single greatest concern for coral reef managers globally (Marshall and Schuttenberg, 2006) although many equatorial reefs, particularly those located in the centre of reef biodiversity (e.g., Indonesia, Papua New Gui-

\footnotetext{
* Corresponding author. Tel.: +61 747815747; fax: +61 747816722.

E-mail address: morgan.pratchett@jcu.edu.au (M.S. Pratchett).
}

nea, and the Philippines), have as yet, been largely unaffected by climate-induced coral bleaching (Wilkinson, 2004). Rather, there are significant natural and direct anthropogenic disturbances that pose a greater threat to biodiversity and ecosystem function within these regions (Baird et al., 2005). For example, outbreaks of A. planci continue to occur throughout the Indo-Pacific region (e.g., Lourey et al., 2000; Sweatman et al., 2004; Pratchett, 2005; Baine, 2006), causing significant coral mortality and adding to the world-wide degradation of coral reef environments (Goldberg and Wilkinson, 2004). Outbreaks of $A$. planci remain the principal cause of longterm coral loss at many locations in the Pacific, including Palau, Guam and Fiji (Bruno and Selig, 2007).

The Indo-Pacific Archipelago represents a diversity hotspot for marine communities and species (Allen, 2007). These regions include many species with life history traits such as limited ranges or habitat specialisation which make them vulnerable to extinction (Jones et al., 2004; Munday, 2004). Coral loss caused by outbreaks of $A$. planci may represent a significant threat to coral reef biodiversity, but few countries have monitoring programs to quantify the abundance of sea stars and the damage caused. Outbreaks remain very poorly understood phenomena and the issue of whether or not outbreaks have an anthropogenic origin remains unresolved. Pratchett (2005) showed that outbreaks of A. planci may arise through the gradual accumulation of successive cohorts of sea stars, in which case proximal causes may be very subtle and 
difficult to detect. If outbreaks of $A$. planci are anthropogenicallyinduced (e.g., Brodie et al., 2005), then there is an increased incentive to try and manage effects of outbreaks on coral reef ecosystems. Moreover, the threat of climate impacts provides renewed incentives to manage and mitigate against all other sources of coral mortality, because minimising coral loss is critical to maximising their adaptive potential and resilience to future unknown disturbances (Marshall and Schuttenberg, 2006). For these reasons, a much greater effort is required to document and understand population dynamics and effects of $A$. planci on coral and the associated reef fauna, especially within the Indo-Pacific Archipelago.

Acanthaster planci is a natural inhabitant on coral reefs throughout the Indian and Pacific Oceans and mostly occurs at very low densities (typically $<1 /$ hectare) (Birkeland and Lucas, 1990). However, outbreak densities of $A$. planci (up to $20,000 /$ hectare) have been reported throughout much of their geographic range including Panama (Glynn, 1974, 1976), Micronesia (Chesher, 1969; Colgan, 1987), southern Japan (Keesing, 1992), the Great Barrier Reef (e.g., Moran et al., 1988; Reichelt et al., 1990), Cocos-Keeling Islands (Colin, 1977) and the Red Sea (Ormond and Campbell, 1974). Incidences of outbreaks are most concentrated in the western Pacific (Moran, 1986), and until very recently, there have been few reports of outbreaks in Papua New Guinea (PNG) or Indonesia (Quinn and Kojis, 1987; Lane, 1996; Tomascik et al., 1997). Prior to 2005, there is only a single published paper on high densities of $A$. planci in PNG (Pyne, 1970), but since then outbreaks have been reported from Bootless Bay and Milne Bay, in southern PNG (Baine, 2006), and high densities have occasionally been observed at several locations in northern PNG, such as Kimbe Bay (Jones et al., 2004).

Outbreaks of $A$. planci can cause massive and widespread coral depletion (e.g., Pearson and Endean, 1969; Chesher, 1969; Randall, 1973; Colgan, 1987) though outbreaks vary greatly, not only in their intensity and magnitude, but also in their effects on coral communities (Moran, 1986). At Molokai Island, Hawaii, for example, outbreak densities of $A$. planci persisted for more than 18 months (1969-1970), but had negligible impacts on the abundance of scleractinian corals (Branham et al., 1971). Incidences of extensive coral depletion caused by outbreaks of $A$. planci have been mostly restricted to the GBR, Micronesia and southern Japan (Moran, 1986; Birkeland and Lucas, 1990), possibly because coral communities in these locations are dominated by Acropora spp. (Family Acroporidae), which are particularly susceptible to crown-of-thorns predation (Glynn, 1974, 1976; De'ath and Moran, 1998; Pratchett, 2007).

Acanthaster planci are very selective in their choice of prey (Glynn, 1974; Ormond et al., 1976; De'ath and Moran, 1998; Pratchett, 2001, 2007), and their feeding preferences are fundamental in determining their effects on coral communities. In general, Acropora spp. are among the most preferred prey corals and Porites spp. are least preferred (e.g., De'ath and Moran, 1998; Pratchett, 2007). However, there are many factors that influence feeding preferences of $A$. planci, including the nutritional content and growth form of corals, coral defences (e.g., mesenterial filaments, nematocysts and secondary metabolites), host defence by crustacean symbionts, the distribution and abundance of corals, and prior conditioning and learnt behaviour of the sea stars (reviewed by Moran, 1986; Birkeland and Lucas, 1990). If A. planci feed mostly on fast growing corals, which also recruit abundantly, (e.g., Acropora spp.) recovery of coral communities may be relatively fast (5-10 years). However, A. planci do sometimes feed on very old colonies of slow-growing coral species, such as Porites spp. (Done, 1985).

The purpose of this study was to describe the distribution and abundance of $A$. planci in Bootless Bay, southern Papua New Guinea. The study was undertaken in March 2006, 6 months after the initial reports of large aggregations of $A$. planci and following significant localised efforts to control the outbreaks; divers from Motupore Island Research Station and Loloata Island Resort removed (hand-collected) or killed (injected with sodium bisulphate) almost 10,000 individual sea stars between September 2005-March 2006. In this study, patterns of abundance and the size structure of $A$. planci populations were studied to assess whether the outbreak resulted from a single massive influx of new recruits (e.g., Zann et al., 1987), or the progressive accumulation of individuals across multiple cohorts (e.g., Pratchett, 2005). Moreover, the study examined the incidence of recent coral mortality in Bootless Bay to assess the extent and magnitude of coral depletion that was potentially caused by the recent outbreak of A. planci.

\section{Materials and methods}

\subsection{Study sites}

Bootless Bay is a large southerly-facing embayment southeast of Port Moresby, Papua New Guinea. This study was principally conducted at three inshore reefs: Loloata, Manunouha and Motupore. Sampling was conducted in areas of well developed fringing reefs; carbonate platforms that extend seaward from the shoreline and terminate in a well-defined reef crest (Fig. 1). Sampling was also conducted at several sites along the Sunken Barrier Reef, situated $3-5 \mathrm{~km}$ from the mainland (Fig. 1). The Sunken Barrier Reef extends $25 \mathrm{~km}$ across Bootless Bay, comprising many shallow reef platforms (10-20 m deep) inter-connected by deeper sections (>50 m deep) of contiguous reef. Sampling for this study was conducted at several sites on a distinct reef platform located due south of Loloata.

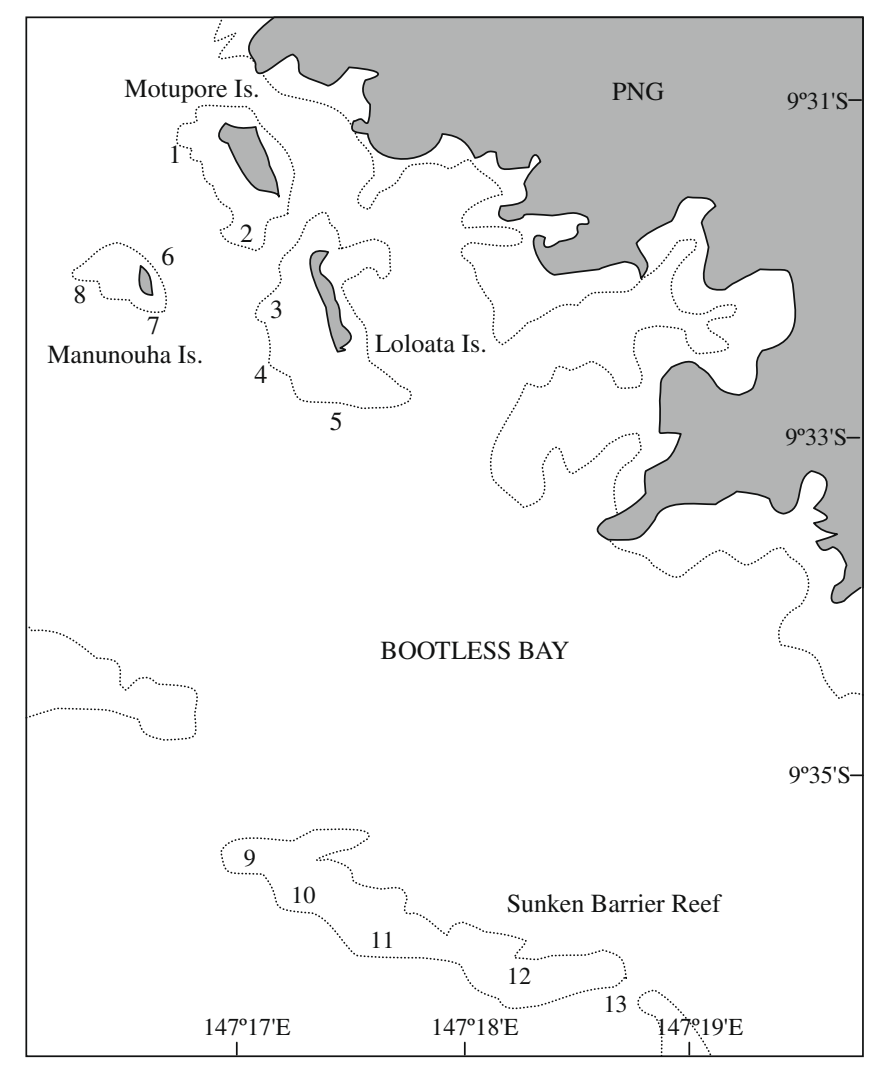

Fig. 1. Map of Bootless Bay showing the four study reefs (Loloata, Manunouha, Motupore, and Sunken Barrier) and specific study sites (numbered 1-13). 


\subsection{Size and abundance of A. planci}

To document spatial variation in the size and abundance of $A$. planci, sampling was conducted on the reef crest (1.5-6 $\mathrm{m}$ depth) and reef slope (6-12 $\mathrm{m}$ depth) at 2-3 sites on each of the inshore reefs (Loloata, Manunouha, and Motupore). On the Sunken Barrier Reef, sampling was conducted on the reef crest (5-6 m) and reef slope (12-15 $\mathrm{m})$ at three sites, as well as along the reef top (10$15 \mathrm{~m}$ depth) at two deeper sites (sites 9 and 12). Four replicate $50 \times 4 \mathrm{~m}$ belt transects were surveyed in each zone at each site. All transects were run from haphazardly selected starting points and run parallel to the reef crest. A total of 96 transects, with a total sample area of $19,200 \mathrm{~m}^{2}$, were surveyed during the course of the study.

To maximise detection of $A$. planci, divers moved very slowly ( $<5 \mathrm{~m}$ per minute) along each side of the transect tape carefully searching within and under all coral colonies for cryptic individuals. We also utilized a depletive sampling regime, whereby sea stars were collected and removed from the transect area once detected. A second diver then resurveyed the same area to maximise detection of further cryptic individuals. The number of sea stars detected by the second diver was consistently very low ( $<2$ per transect), indicating that further searching would have not greatly increased estimates of local seastar densities. In addition to recording the abundance of $A$. planci, we also recorded the size of every sea star detected on each transect. Sea stars were carefully removed from among coral branches or within crevices using a long wire hook. Once extracted, sea stars were laid flat on the reef matrix where they were measured. Body size of individual sea stars was recorded as the maximum whole body diameter (from the tips of opposite arms) to the nearest $\mathrm{cm}$, following Pratchett (2005).

Spatial variation in the size and abundance of $A$. planci was analysed using log-linear analyses and analysis of variance (ANOVA), respectively. Log-linear analysis was used to test whether the size structure of $A$. planci varied among reefs. Using reef as the categorical variable, the size categories were run through a categorical data analysis to ascertain whether the reefs should be examined independently. The response function in this model was the cumulative logit, which recognises the order in the size classes. Variation in mean abundance of $A$. planci was analysed using a mixed model three-way ANOVA, exploring variation among reefs (four levels, fixed), sites (three levels, random) and zones (two levels; crest and slope fixed). Count data were square root transformed prior to analysis to normalize the data and improve homogeneity of variances.

\subsection{Coral surveys}

Establishing the extent and severity of coral depletion caused by recent aggregations of $A$. planci in Bootless Bay was greatly hindered by a lack of data on coral cover and composition prior to September 2005. Therefore, to document likely changes in cover and composition of coral communities, we quantified area cover of recently dead coral colonies. For the most part, dead corals observed on the reefs in Bootless Bay had only a thin layer of turf algae covering the skeleton and were still identifiable to genus or species, indicating that these corals probably died within the last 6 months (sensu Hutchings, 1986). The few dead corals with conspicuous signs of biological erosion were deemed to have died prior to September 2005 and were not counted. Estimates of coral mortality based on cover of recently dead corals may under-estimate actual coral loss by failing to account for coral skeletons that were dislodged following whole colony mortality.

Percentage cover of live and recently killed scleractinian corals was estimated using $50-\mathrm{m}$ point intercept transects, following Dodge et al. (1982). Coral surveys were conducted along all tran- sects ( $N=96$ transects) used to quantify densities of $A$. planci. A total of 100 points were surveyed on each transect, spaced at $0.5 \mathrm{~m}$ intervals along each transect. Fixed-distance point census was used in preference to random point census, as used during video census (Ryan, 2004) to maximise the distance between successive sampling points and thereby reduce autocorrelation among sample points. Any live or recently dead scleractinian corals underlying each point were identified to genus or species, where possible.

\section{Results}

\subsection{Abundance of A. planci}

In March 2006, average densities of $A$. planci in Bootless Bay were $3.23 / 200 \mathrm{~m}^{2}( \pm 0.44 \mathrm{SE})$, equating 162 /hectare. Greatest densities of $A$. planci were found on the inshore reefs of Bootless Bay around Manunouha Island $\left(4.62 / 200 \mathrm{~m}^{2} \pm 1.06 \mathrm{SE}\right)$, Loloata Island $\left(4.04 / 200 \mathrm{~m}^{2} \pm 0.80 \mathrm{SE}\right)$ and Motupore Island $\left(3.62 / 200 \mathrm{~m}^{2} \pm 0.99\right.$ $\mathrm{SE})$. In contrast, mean densities of $A$. planci at Sunken Barrier Reef were only $1.41 / 200 \mathrm{~m}^{2}( \pm 0.66 \mathrm{SE})$, and there were no sea stars recorded at two (out of five) sites (Fig. 2). Average densities of $A$. planci were also generally higher on the reef crest (3.63 sea stars per $\left.200 \mathrm{~m}^{2} \pm 0.61 \mathrm{SE}\right)$ compared to the reef slope $(2.88 /$ $200 \mathrm{~m}^{2} \pm 0.65 \mathrm{SE}$ ). However, variation in the abundance of $A$. planci was only significant among sites within reefs (Table 1) where abundance of $A$. planci varied up to 7-fold among sites separated by $<1 \mathrm{~km}$. At Loloata for example, mean densities of $A$. planci ranged from $1.12 / 200 \mathrm{~m}^{2}( \pm 0.29 \mathrm{SE})$, up to $8.62 / 200 \mathrm{~m}^{2}( \pm 1.10 \mathrm{SE})$ (Fig. 2).

\subsection{Size of A. planci}

Maximum diameter of $A$. planci recorded within Bootless Bay ranged from $7 \mathrm{~cm}$ to $38 \mathrm{~cm}$. However, most sea stars (82.3\%) were between $20-35 \mathrm{~cm}$ diameter, and only a very small proportion of individuals ( $<2 \%$ ) were $>35 \mathrm{~cm}$ or $<10 \mathrm{~cm}$ total diameter. The overall size frequency distribution had a conspicuous single mode (25$30 \mathrm{~cm}$ diameter), and size structure was approximately normally distributed around a mean size of $24.7 \mathrm{~cm}$ diameter (Fig. 3). There was slight, but significant variation in the size structure of $A$. planci among the four reefs (Chi-square, $\chi^{2}=11.2382, d f=3, p=0.01$ ). This was due to very limited numbers of smaller sea stars on the Sunken Barrier Reef, where only six (13\%) out of 44 individuals were $<20 \mathrm{~cm}$ diameter. In contrast, smaller A. planci $(<20 \mathrm{~cm}$ diameter) accounted for $19-27 \%$ of sea stars recorded on the three inshore reefs (Loloata, Manunouha, and Motupore).

\subsection{Coral mortality}

In March 2006, average coral cover in Bootless Bay was 19.14\% $( \pm 1.57 \mathrm{SE})$ and the dominant coral taxa were massive Porites. Average cover of recently killed and readily identifiable coral skeletons, assumed to have been killed by recent infestations of $A$. planci, was $23.26 \%( \pm 1.9 \mathrm{SE})$. These corals varied in the extent to which they had been colonised by turf algae, but had not yet been colonised by either crustose coralline or fleshy macro-algae, which tends to occur 15-20 months after coral death (Diaz-Pulido and McCook, 2002). The most conspicuous and abundant of these dead corals were Acropora florida and A. hyacinthus (Fig. 4). Estimates of proportional mortality within each of 29 coral taxa, range from $9 \%$ for Diploastrea up to $100 \%$ mortality for A. florida gp. (Fig. 4). Among families of corals, proportional mortality was highest for Acroporidae and the Pocilloporidae, whereas rates of mortality recorded among Poritiidae were generally lower than all other families of corals (Fig. 4). 


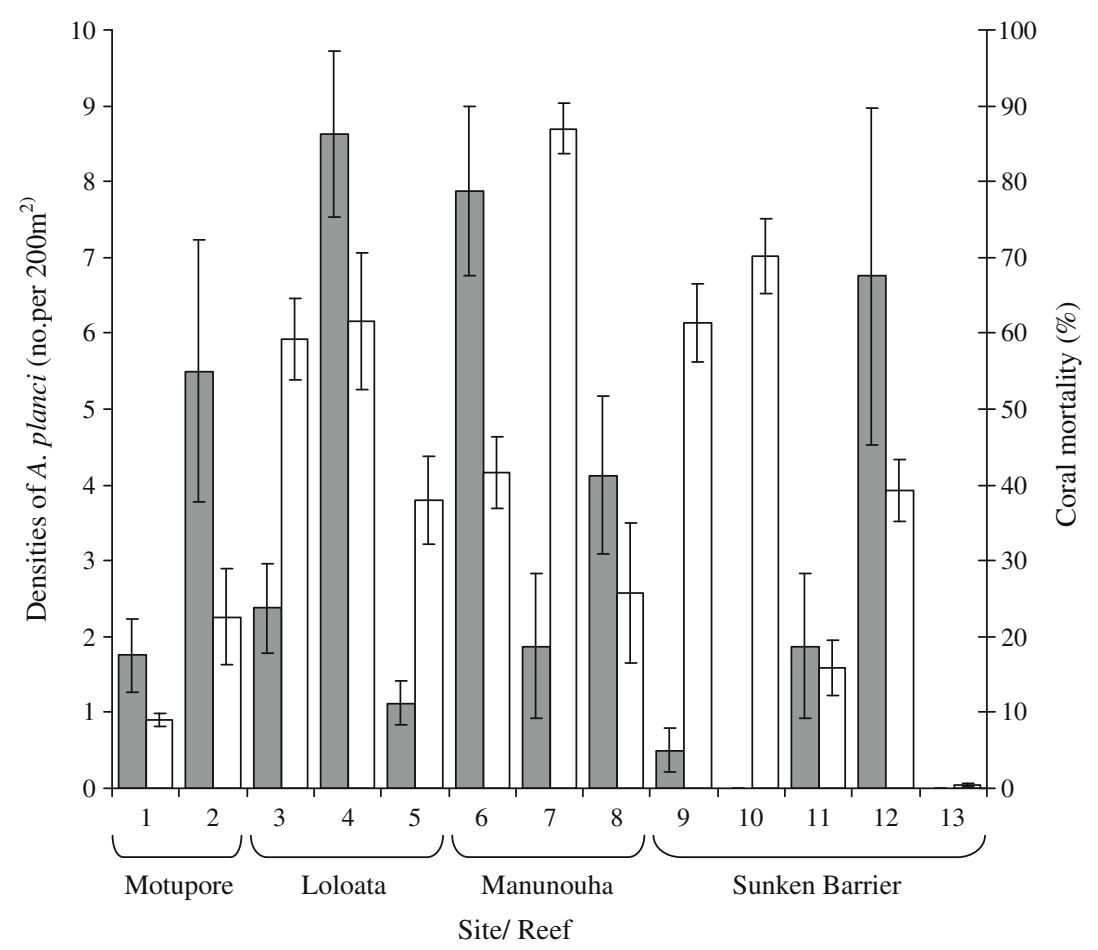

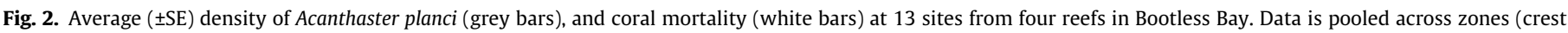
and slope).

Table 1

Three-way ANOVA to test for variation in the abundance of $A$. planci among reefs (four reefs), sites (13 sites) and zones (crest, slope, and top). Data were unbalanced because not all zones occurred at all of the sites. Abundance was also square root transformed prior to the analysis to improve normality and homogeneity.

\begin{tabular}{lrrll}
\hline Source & $d f$ & MS & $F$ & $p$ \\
\hline Reef & 3 & 10.25 & 2.19 & 0.18 \\
Site (reef) & 7 & 4.76 & 4.99 & 0.0001 \\
Zone & 1 & 2.19 & 2.29 & 0.13 \\
Site (reef) $*$ zone & 7 & 0.95 & 1.43 & 0.21 \\
Reef $*$ zone & 3 & 0.96 & 1.01 & 0.39 \\
Error & 72 & 0.67 & & \\
\hline
\end{tabular}

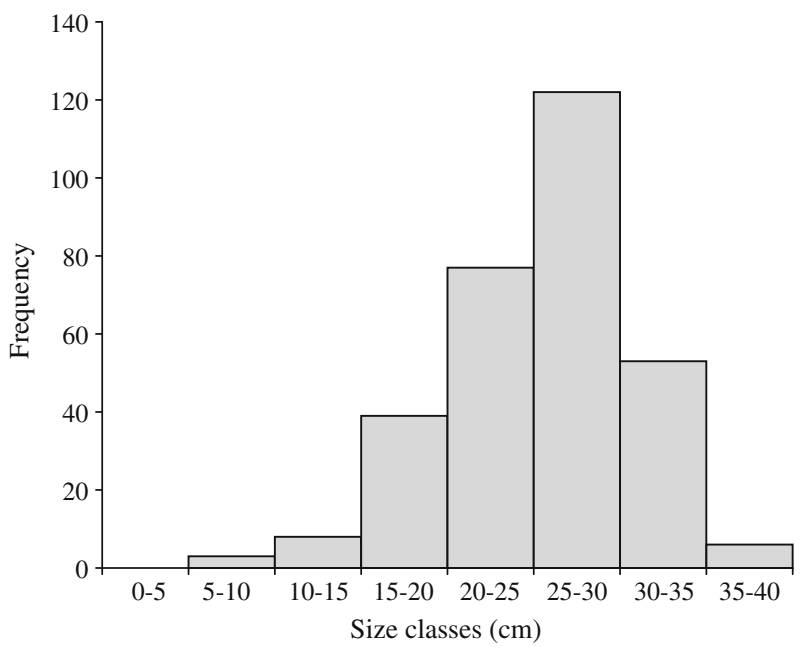

Fig. 3. Overall size structure for all A. planci ( $n=311$ seastars) recorded across all four reefs (Motupore, Loloata, Manunouha and Sunken Barrier Reef) within Bootless Bay, March 2006.
Percentage cover of dead corals varied greatly among reefs, ranging from $32.5 \%( \pm 3.1 \mathrm{SE})$ at Loloata, down to $15.1 \%( \pm 2.6 \mathrm{SE})$ at Manunouha, $12.7 \%( \pm 1.6 \mathrm{SE})$ at the Sunken Barrier, and $6.8 \%$ $( \pm 1.3 \mathrm{SE})$ at Motupore. Coral mortality was also highly variable among sites within reefs. Most notably, at site 10 on the Sunken Barrier Reef, percentage cover of dead corals was $34.8 \%$ ( $\pm 1.9 \mathrm{SE}$ ) compared to just $14.0 \%( \pm 1.4 \mathrm{SE})$ for live corals, which equates to $70.1 \%$ coral mortality (Fig. 2 ). In contrast, dead coral cover was only $0.5 \%( \pm 0.18 \mathrm{SE})$ at site 13 , where live coral cover was $45.3 \%( \pm 4.1$ $\mathrm{SE})$. Between zones, the area cover of dead coral was consistently higher on the reef crest compared to the reef slope, mainly due to extensive mortality of $A$. hyacinthus gp. that predominate in reef crest habitats.

Spatial variation in the estimates of recent coral mortality do not relate to recorded densities of $A$. planci at each site in March 2007. In March 2006, there were some sites where coral mortality appears disproportionately high relative to densities of $A$. planci (sites 5, 7, 9 and 10), and others where coral mortality is relatively low given local densities of sea stars (sites 2 and 6 ). Sites with high levels of coral mortality but low densities of A. planci (sites 5, 7, 9 and 10) were mostly impacted at the start of the outbreak episode, and densities of sea stars are now low due to intensive control efforts and/or sea stars have moved to new locations. In contrast, sites with high densities of $A$. planci, but low levels of coral mortality are probably sites where infestations are relatively recent and may still cause significant coral loss.

\section{Discussion}

Despite significant recent control efforts, mean densities of $A$. planci recorded in Bootless Bay in March 2006 were well above the densities (15/hectare) used to characterise reef-wide outbreaks on the Great Barrier Reef (Moran and De'ath, 1992) and represent the first reported outbreak of $A$. planci in this region. Recent and seemingly unprecedented outbreaks of $A$. planci have also been re- 


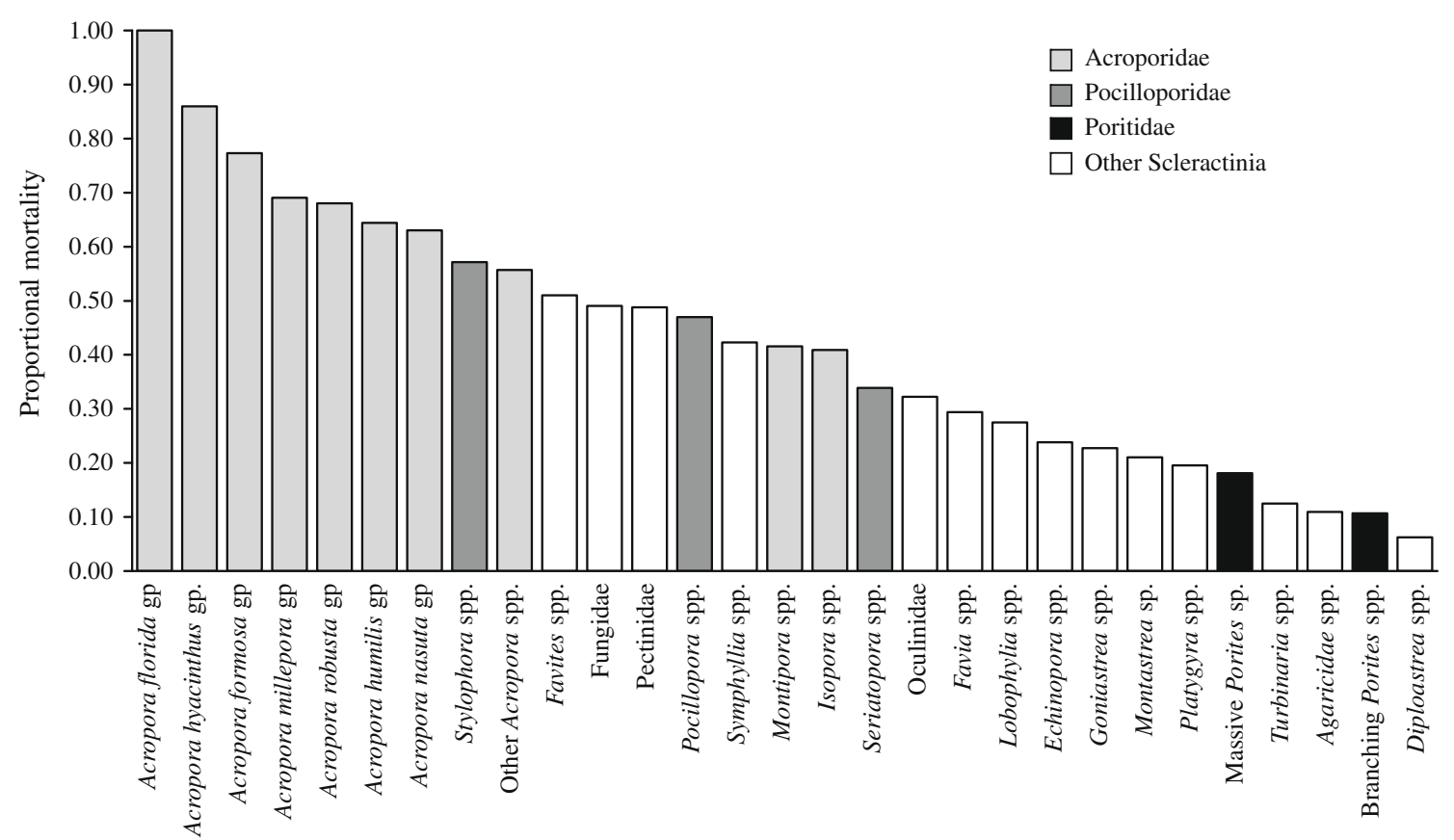

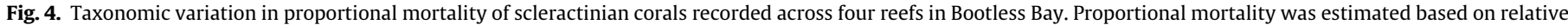
abundance of live versus dead coral colonies with dead coral colonies assumed to have died within 6 months from September 2006 to March 2007.

ported in several other locations throughout the Indo west Pacific (Banda Islands, UNESCO, 2002; northern Sulawesi, DeVantier and Turak, 2004; northern Sumatra, Herdiana et al., 2008), which may signify important changes in environmental conditions (e.g., declining water quality, increased sedimentation, changing hydrodynamic patterns, or increasing ocean temperatures) that either promote delivery of larvae and/or enhance post-settlement survival of $A$. planci throughout this region (sensu Brodie et al., 2005). Notably, the location of this study is close to several major rivers within the catchments of the most heavily populated region of PNG. However, there has not been any direct monitoring of changing water quality which could be used to ascribe causes for the recent outbreak of $A$. planci in Bootless Bay. There is also the possibility that over-fishing in these areas has ultimately lead to a release from predation for $A$. planci, following Dulvy et al. (2004) and Sweatman (2008), as these study locations are close very high population densities and subject to heavy fishing pressure (Wilkinson, 2004).

The outbreak population of $A$. planci in Bootless Bay comprised individuals ranging in size from $7 \mathrm{~cm}$ to $38 \mathrm{~cm}$ in diameter, potentially representing two distinct cohorts. Sea stars $<25 \mathrm{~cm}$ are generally considered less than 2 years old, whereas sea stars between 35 and $40 \mathrm{~cm}$ are generally regarded as $>4$ years old (Stump, 1996). It is likely, therefore, that recruitment of $A$. planci in Bootless Bay commenced as early as 2002. However, the overall size structure of the outbreak population has a single mode with the majority of sea stars (82.3\%) between 20 and $35 \mathrm{~cm}$ in diameter, which represents the initial and dominant cohort. Therefore, the current outbreak appears to have arisen mostly from a single massive recruitment event, which is typical of many A. planci outbreaks (e.g., Chesher, 1969; Branham et al., 1971; Zann et al., 1987), as opposed to the prolonged and gradual increase in seastar densities recorded on some reefs which are classified as primary outbreaks (Pratchett, 2005). Rapid increases in the abundance of A. planci almost certainly represent a secondary outbreak (Johnson, 1992), caused by spawning activities of large aggregations of adult sea stars on upstream reefs (Moran, 1986; Birkeland and Lucas, 1990). Recent active outbreaks of $A$. planci have been reported in both Torres Strait, northern GBR (T. Done, Pers. Comm), and at Milne Bay, southern PNG (e.g., Baine, 2006), both of which are potential sources of recruits for A. planci populations in Bootless Bay. Population genetics may prove useful to establish the connectivity of disparate populations of A. planci (e.g., Yasuda et al., 2006) to better understand the origin of outbreaks. However, such studies are only just beginning, following the recent development of microsatellite markers for A. planci (Yasuda et al., 2006).

Whatever the cause, current outbreaks of $A$. planci have almost certainly contributed to extensive coral depletion throughout Bootless Bay. There was no apparent relationship between current densities of sea stars and rates of coral loss reported at each site, but coral mortality reflects the cumulative impacts of $A$. planci throughout the last 6 months and the distribution and abundance of $A$. planci has been highly variable during this period. Large aggregations of $A$. planci can cause extensive coral mortality over vast reef areas by continually moving from one area to the next and sequentially depleting either all or only the most preferred prey corals (Colgan, 1987). In the 1960's, outbreaks of A. planci killed $80-100 \%$ of corals across entire reefs in both Guam (Chesher, 1969) and on the GBR (Pearson and Endean, 1969). One factor that determines the devastation on the reef is the coral composition prior to the outbreak. Most notably, a reef that is dominated by highly preferred coral species, such as Acropora is likely to be much more affected than a reef dominated by Porites and/or other massive species (De'ath and Moran, 1998). Acanthaster planci will feed on non-preferred coral species, such as Porites, but only after they have exhausted their preferred prey resources (Pratchett, 2007).

Recent coral mortality in Bootless Bay, since the onset of A. planci outbreaks, is estimated to be $>55 \%$, based on the area cover of dead and intact coral skeletons. We argue that these dead but intact corals must have died relatively recently, at most 12 months ago and mostly within weeks to months, because colonisation by algae was minimal and the fine structure which made them individually recognisable had not even begun to erode. Assuming these coral have died within the last few months it is still not certain that this was caused by localised feeding activities of A. planci. Several 
factors, including coral disease, predation by other corallivores, and/or bleaching, may have contributed to increased coral mortality during this period. However, it is notable the coral mortality was negligible at sites (1,2 and 13) where A. planci had only recently or never been reported, suggesting most (if not all) of the dead intact corals recorded in Bootless Bay had been eaten by recent outbreaks of $A$. planci. Variation in levels of coral mortality recorded for different coral taxa is also largely consistent with patterns of prey preferences known for A. planci (De'ath and Moran, 1998; Pratchett, 2001, 2007).

Acanthaster planci are well adapted to feed on a wide range of different corals, but often exhibit striking preference for a small suite of available prey species. Mostly, A. planci appears to favour corals of the family Acroporidae and particularly Acropora spp. (Keesing, 1992; De'ath and Moran, 1998; Pratchett, 2001, 2007). Accordingly, there were significant declines in percentage cover of all Acropora taxa in Bootless Bay. The worst affected taxa were $A$. florida, and $A$. hyacinthus. However, declines in live coral extended across a wide range of taxa, reflecting the severity of the outbreak. Feeding preferences of $A$. planci are fundamental in determining their effects on coral communities, especially during moderate outbreaks and when food is abundant. However, when outbreaks are particularly severe or food becomes scarce, $A$. planci will eat most coral species (Moran, 1986).

Despite significant changes in both coral cover and composition, the recovery of coral communities in Bootless Bay could be very rapid. Estimates of the time required for coral communities to recover from outbreaks of $A$. planci (and other major disturbances) are highly varied, ranging from $<5$ years to $>1000$ years (Pearson, 1981; Lourey et al., 2000). In extreme cases, coral communities may never regain their initial structure, even where coral cover returns to pre-disturbance levels (Endean et al., 1988; Berumen and Pratchett, 2006). The rate and extent of recovery in coral communities depends primarily on the amount of damage that has occurred. Completely denuded reefs recover much more slowly than reefs in which at least some corals survive to grow and reproduce (Connell, 1997). Recovery also depends on the types of corals affected (Done, 1985). In Bootless Bay, effects of $A$. planci were comparatively mild and most coral taxa persisted. Further, effects were mostly restricted to fast growing branching corals (e.g., Acropora spp.) as opposed to slow-growing massive species (e.g., Porites spp.) increasing the likelihood that recovery will occur quickly (Pearson, 1981; Done, 1985). Assuming that outbreaks of A. planci end soon (either through human intervention or natural population dynamics) there is a strong possibility that coral communities in Bootless Bay will not suffer any long-term effects of the recent outbreak.

\section{Conclusions}

In conclusion, high levels (up to $85 \% \pm 0.10 \mathrm{SE}$ ) of recent coral mortality were recorded throughout Bootless Bay, associated with a severe and seemingly unprecedented outbreak of $A$. planci. The outbreak of $A$. planci most likely resulted from a single massive influx of recruits spawned on nearby reefs with active outbreaks. Coral loss caused by this outbreak was significant, and selective removal of Acropora caused major changes in overall habitat structure. It is likely, however, that coral cover will recover quickly given that coral coral cover is still $19.1 \%$, and only A. florida gp. has experienced local extinction, thus far. Ongoing monitoring of these reefs will be essential to assess whether populations of $A$. planci are being maintained through continual input of new larvae, and to further refine predicted effects of $A$. planci in these important reef environments, which support a high diversity of coral reef organisms (Baine and Harasti, 2007).

\section{Acknowledgment}

This research was conducted towards a MAppSc degree by $\mathrm{T}$. Schenk, at James Cook University. This research was supported by ARC funding to MSP and AHB. Field sampling was conducted with in-kind support and extensive logistic assistance from Motupore Island Research Centre and Loloata Island Resort. This manuscript benefited greatly from discussions with H. Sweatman, T. Done and M. Yasuda.

\section{References}

Allen, G.R., 2007. Conservation hotspots of biodiversity and endemism for IndoPacific coral reef fishes. Aquatic Conservation: Marine and Freshwater Ecosystems 18, 541-556.

Baine, M.S.P., 2006. A major outbreak of crown-of-thorns starfish in Bootless Bay, Central Province, Papua New Guinea. Coral Reefs 25, 607

Baine, M.S.P., Harasti, D., 2007. The Marine Life of Bootless Bay. Papua New Guniea, University of Papua New Guinea, Port Moresby.

Baird, A.H., Campbell, S.J., Anggoro, A.W., Ardiwijaya, R.L., Fadli, N., Herdiana, Y., Kartawijaya, T., Mahyiddin, D., Mukminin, A., Pardede, S.T., Pratchett, M.S., Rudi, E., Siregar, A.M., 2005. Acehnese reefs in the wake of the Asian tsunami. Current Biology 15, 1926-1930.

Berumen, M.L., Pratchett, M.S., 2006. Persistent disturbance and long-term shifts in the structure of fish and coral communities at Tiahura Reef, Moorea. Coral Reefs 25, 647-653.

Birkeland, C., Lucas, J.S., 1990. Acanthaster planci: Major Management Problem of Coral Reefs. CRC Press, Boston.

Branham, J.M., Reed, S.A., Bailey, J.H., 1971. Coral-eating sea stars Acanthaster planci in Hawaii. Science 172, 1155-1157.

Brodie, J., Fabricius, K., De'Ath, G., Okaji, K., 2005. Are increased nutrient inputs responsible for more outbreaks of crown-of-thorns starfish? An appraisal of the evidence. Marine Pollution Bulletin 51, 266-278.

Bruno, J.F., Selig, E.R., 2007. Regional decline of coral cover in the Indo-Pacific: timing, extent, and subregional comparisons. PLoS One 2 (8), e711.

Bruno, J.F., Selig, E.R., Casey, K.S., Page, C.A., Willis, B.L., Harvell, C.D., Sweatman, H., Melendy, A.M., 2007. Thermal stress and coral cover as drivers of coral disease outbreaks. PLoS Biology 5, 1220-1227.

Chesher, R.H., 1969. Destruction of Pacific corals by the sea star Acanthaster planci. Science 18, 280-283.

Colgan, M.W., 1987. Coral reef recovery on Guam (Micronesia) after catastrophic predation by Acanthaster planci. Ecology 68, 1592-1605.

Colin, L.P., 1977. The reefs of Cocos-Keeling Atoll. Eastern Indian Ocean. In: Proceedings of the 3rd International Coral Reef Symposium, vol. 1, pp. 35-42.

Connell, J.H., 1997. Disturbance and recovery of coral assemblages. Coral Reefs 16, S101-S113.

DeVantier, L., Turak, E., 2004. Managing Marine Tourism - Bunaken National Park and Adjacent Waters, North Sulawesi, Indonesia 2003. USAID.

De'ath, G., Moran, P.J., 1998. Factors affecting the behaviour of crown-of-thorns starfish (Acanthaster planci L.) on the Great Barrier Reef: 2: feeding preferences. Journal of Experimental Marine Biology and Ecology 220, 107-126.

Diaz-Pulido, G., McCook, L.J., 2002. The fate of bleached corals: patterns and dynamics of algal recruitment. Marine Ecology Progress Series 232, 115-128.

Dodge, R.E., Logan, A., Antonius, A., 1982. Quantitative reef assessment studies in Bermuda: a comparison of methods and preliminary results. Bulletin of Marine Science $32,745-760$.

Done, T.J., 1985. Effects of two Acanthaster outbreaks on coral community structure: the meaning of devastation. In: Proceedings of the 5th International Coral Reef Symposium, vol. 5 , pp. 315-320.

Dulvy, N.K., Freckleton, R.P., Polunin, N.V.C., 2004. Coral reef cascades and the indirect effects of predator removal by exploitation. Ecology Letters 7, 410416.

Endean, R., Cameron, A.M., DeVantier, L.M., 1988. Acanthaster planci predation on massive corals: the myth of rapid recovery of devastated reefs. In: Proceedings of the 6th International Coral Reef Symposium, vol. 2, pp. 143-148.

Glynn, P.W., 1974. The impact of Acanthaster on corals and coral reefs in the eastern Pacific. Environmental Conservation 1, 295-303.

Glynn, P.W., 1976. Some physical and biological determinants of coral community structure in the Eastern Pacific. Ecological Monographs 46, 431-456.

Goldberg, J., Wilkinson, C., 2004. Global threats to coral reefs: coral bleaching, global climate change, disease, predator plagues, and invasive species. In: Wilkinson, C. (Ed.), Status of Coral Reefs of The World. Australian Institute of Marine Science, Townsville, pp. 67-92.

Herdiana, Y., Kartawijaya, T., Ardiwijaya, R.L., Setiawan, F., Prasetia, R., Pardede, S.T., Campbell, S.J., 2008. Ecological survey on coral reefs of Simeulue and Banyak Islands - Aceh 2007. Wildlife Conservation Society - Indonesia Marine Program, Bogor, Indonesia.

Hughes, T.P., Connell, J.H., 1999. Multiple stressors on coral reefs: a long-term perspective. Limnology and Oceanography 44, 932-940.

Hughes, T.P., Baird, A.H., Bellwood, D.R., Card, M., Connolly, S.R., Folke, C., Grosberg, R., Hoegh-Guldberg, O., Jackson, J.B.C., Kleypas, J., Lough, J.M., Marshall, P., Nystrom, M., Palumbi, S.R., Pandolfi, J.M., Rosen, B., Roughgarden, J., 2003. 
Climate change, human impacts, and the resilience of coral reefs. Science 301 , 929-933.

Hutchings, P.A., 1986. Biological destruction of coral reefs: a review. Coral reefs 4, 239-252.

Johnson, C., 1992. Settlement and recruitment of Acanthaster planci on the Great Barrier Reef: a question of process and scale. Australian Journal of Marine and Freshwater Research 43, 611-627.

Jones, G.P., McCormick, M.I., Srinivasan, M., Eagle, J.V., 2004. Coral declines threaten fish biodiversity in marine reserves. Proceedings of the National Academy of Science, USA 101, 8251-8253.

Keesing, J.K., 1992. Influence of persistent sub-infestation density Acanthaster planci (L.) and high density Echinometra mathaei (de Blainville) populations on coral reef community structure in Okinawa, Japan. In: Proceedings of the 7th International Coral Reef Symposium, vol. 2, pp. 769-779.

Knowlton, N., 2001. The future of coral reefs. Proceedings of the National Academy of Science, USA 98, 5419-5425.

Lane, D.J.W., 1996. A crown-of-thorns outbreak in the eastern Indonesian Archipelago, February 1996. Coral Reefs 15, 209-210.

Lourey, M.J., Ryan, D.A.J., Miller, I.R., 2000. Rates of decline and recovery of coral cover on reefs impacted by, recovering from and unaffected by crown-of-thorns starfish Acanthaster planci: a regional perspective of the Great Barrier Reef. Marine Ecology Progress Series 196, 179-186.

Marshall, P.A., Schuttenberg, H., 2006. Adapting coral reef management in the face of climate change. Coastal and Estuarine Studies 61, 223-241.

Moran, P.J., 1986. The Acanthaster phenomenon. Oceanography and Marine Biology: An Annual Review 24, 379-480.

Moran, P.J., De'ath, G., 1992. Estimates of the abundance of the crown-of-thorns starfish Acanthaster planci in outbreaking and non-outbreaking populations on reefs within the Great Barrier Reef. Marine Biology 113, 509-515.

Moran, P.J., Bradbury, R.H., Reichelt, R.E., 1988. Distribution of recent outbreaks of the crown-of-thorns starfish (Acanthaster planci) along the Great Barrier Reef: 1985-1986. Coral Reefs 7, 125-137.

Munday, P.L., 2004. Habitat loss, resource specialization and extinction on coral reefs. Global Change Biology 10, 1642-1647.

Ormond, R.F.G., Campbell, A.C., 1974. Formation and breakdown of Acanthaster planci aggregations in the Red Sea. In: Proceedings of the 2nd International Coral Reef Symposium, vol. 1, pp. 577-590.

Ormond, R.F.G., Hanscomb, N.J., Beach, D.H., 1976. Food selection and learning in the crown-of-thorns starfish Acanthaster planci (L.). Marine Behaviour and Physiology 4, 93-105.

Pearson, R.G., 1981. Recovery and recolonisation of coral reefs. Marine Ecology Progress Series 4, 105-122.

Pearson, R.G., Endean, R., 1969. A preliminary study of the coral predator Acanthaster planci (L.) (Asteroidea) on the GBR. Fisheries Notes 3, 27-55.
Pratchett, M.S., 2001. Influence of coral symbionts on feeding preferences of crownof-thorns starfish. Marine Ecology Progress Series 214, 111-119.

Pratchett, M.S., 2005. Dynamics of an outbreak population of Acanthaster planci at Lizard Island, northern Great Barrier Reef (1995-1999). Coral Reefs 24, 453462.

Pratchett, M.S., 2007. Feeding preferences of Acanthaster planci (L.) under controlled conditions of food availability. Pacific Science 61, 113-120.

Pyne, R.R., 1970. Notes on the crown-of-thorns starfish: its distribution in Papua and New Guinea (Echinodermata: Asteroidea: Acanthasteridae). Papua New Guinea Journal of Agriculture, Forestry and Fisheries 21, 128-138.

Quinn, N.J., Kojis, B.L., 1987. Distribution and abundance of Acanthaster planci in Papua New Guinea. Bulletin of Marine Science 41, 576-578.

Randall, R.H., 1973. Distribution of corals after Acanthaster planci (L.) infestation at Tanguisson Point, Guam. Micronesica 3, 213-222.

Reichelt, R.E., Bradbury, R.H., Moran, P.J., 1990. Distribution of Acanthaster planci outbreaks on the GBR between 1966 and 1989. Coral Reefs 9, 97-103.

Ryan, D.A.J., 2004. Point sampling strategies for estimating coverage from benthic video transects. Environmetrics 15, 193-207.

Stump, R., 1996. An investigation to describe population dynamics of Acanthaster planci (L.) around Lizard Island, Cairns section. GBR Marine Park, CRC Reef Townsville.

Sweatman, H., 2008. No-take reserves protect coral reefs from predatory starfish Current Biology 18, R598-R599.

Sweatman, H., Abdo, D., Burgess, S., Cheal, A., Coleman, G., Delean, S., Emslie, M. Miller, I., Osborne, K., Oxley, W., Page, C., Thompson, A., 2004. Long-term Monitoring of the Great Barrier Reef. Australian Institute of Marine Science, Townsville.

Tomascik, T., Mah, A.J., Nontji, A., Moosa, M.K., 1997. The Ecology of the Indonesia Seas, Part II. The Ecology of Indonesia Series Volume VIII, Periplus Edition (HK) Ltd.

UNESCO, 2002. Report on a rapid ecological assessment of the Banda Islands. Maluku, Eastern Indonesia, Jakarta.

Wilkinson, C., 2004. Status of the Coral Reefs of the World: 2004. Australian Institute of Marine Science, Townsville.

Wilson, S.K., Graham, N.A.J., Pratchett, M.S., Jones, G.P., Polunin, N.V.C., 2006. Multiple disturbances and the global degradation of coral reefs: are reef fishes at risk or resilient? Global Change Biology 12, 2220-2234.

Yasuda, N., Nagai, S., Hamaguchi, M., Lian, C.L., Nadaoka, K., 2006. Development of microsatellite markers for the crown-of-thorns starfish Acanthaster planci. Molecular Ecology Notes 6, 141-143.

Zann, L., Brodie, J., Berryman, C., Naqasima, M., 1987. Recruitment, ecology, growth and behavior of juvenile Acanthaster planci (L.) (Echinodermata: Asteroidea). Bulletin of Marine Science 41, 561-575. 